\title{
N-doped porous carbon capsules with tunable porosity for high-performance supercapacitors
}

\author{
G.A. Ferrero, A. B. Fuertes, M. Sevilla* \\ Instituto Nacional del Carbón (CSIC), P.O. Box 73, Oviedo 33080, Spain \\ *Corresponding author: martasev@incar.csic.es
}

\section{Abstract}

A procedure for the fabrication of $\mathrm{N}$-doped hollow carbon spheres with a high rate capability for supercapacitors has been developed. The approach is based on a nanocasting method and the use of a nitrogen-rich compound (pyrrole) as carbon precursor. The carbon particles thus produced combine a large BET surface area $\left(\sim 1500 \mathrm{~m}^{2} \mathrm{~g}^{-1}\right)$ with a porosity made up of mesopores of $\sim 4 \mathrm{~nm}$ and a high nitrogen content ( $6 \mathrm{wt} \%)$ and a capsule morphology which entails short ion diffusion paths derived from the shell morphology (thickness $\sim 60 \mathrm{~nm}$ ). The porous properties of these hollow particles can be enhanced by means of an additional activation step with $\mathrm{KOH}$. The activation process does not alter the hollow structure or spherical morphology, but strongly modifies the pore structure from a mesoporous network to a microporous one. The N-doped carbon capsules were tested in aqueous and organic electrolytes. In an aqueous medium ( $1 \mathrm{M} \mathrm{H}_{2} \mathrm{SO}_{4}$ ), the mesoporous carbon capsules offer the best performance due to the pseudocapacitive contribution of the $\mathrm{N}$-groups, exhibiting a specific capacitance of $\sim 240 \mathrm{~F} \mathrm{~g}^{-1}$ at $0.1 \mathrm{~A} \mathrm{~g}^{-1}$ and a capacitance retention as high as $72 \%$ at $80 \mathrm{~A} \mathrm{~g}^{-1}$. On the contrary, in an organic electrolyte 
(1 $\mathrm{M} \mathrm{TEABF}_{4} / \mathrm{AN}$ ), where the charge storage mechanism is based on the formation of the electric double-layer, the microporous capsules perform better due to the larger specific surface area. Thus, the microporous carbon capsules display a specific capacitance of up to $141 \mathrm{~F} \mathrm{~g}^{-1}$ at $0.1 \mathrm{~A} \mathrm{~g}^{-1}$ and an outstanding capacitance retention of $93 \%$ for an ultra-high discharge current density of 100 $\mathrm{A} \mathrm{g}^{-1}$

Keywords: carbon, porosity, supercapacitors, capsule, nitrogen-doping. 


\section{Introduction}

Porous carbons are widely employed as electrode materials in electrochemical double-layer capacitors (EDLCs) due to their good electronic conductivity, high chemical stability, low-cost and wide availability, and large surface area/porosity. ${ }^{1-3}$ In these systems, energy storage takes place via the accumulation of electrical charges at the electrode/electrolyte interface. This implies that the stored electrical energy will be proportional to the surface area of the electrode and that, in consequence, carbon materials with large surface areas are to be preferred. However, as shown by different authors, the correlation is not that direct and the pore size has a strong effect on ion adsorption enhancement. ${ }^{4}$ Thereby, for a desired combination of energy and power characteristics, EDLC materials need to combine other several important properties such as an appropriate pore size distribution (micro-mesopores), ${ }^{5,6}$ short diffusional paths, a high electrical conductivity, and good wettability by the electrolyte. Further improvement of their electrochemical performance can be achieved through the incorporation of heteroatoms into the carbon framework. In this respect, it has been reported that $\mathrm{N}$-doped porous carbons exhibit a much better performance as supercapacitors due to an enhancement of their electronic conductivity and surface wettability in addition to pseudo-capacitive effects contributed by nitrogen functional groups. ${ }^{1,2,6,7}$

Although micropores perform better than mesopores in EDLC systems, ${ }^{3}$ large carbon particles with a porosity made up exclusively of narrow micropores are not a good option. The combination of a microporous network and long 
diffusional paths severely limits the ion-transport kinetics resulting in a dramatic reduction in EDLC performance at high current densities, which is the aimed niche of supercapacitors. Consequently, for materials made up of large-size particles (i.e. $>5 \mu \mathrm{m}$ ), the presence of a certain number of mesopores is necessary to accelerate the rate of diffusion by enhancing accessibility to the micropores. $^{8}$

Another way to enhance ion-transport kinetics is by fabricating microporous carbons particles with ultra-small sizes $(<200 \mathrm{~nm})$ that will entail short ion-transport paths. ${ }^{9-12}$ Therefore, a rational strategy for producing highperformance EDLC electrodes would be to design of porous carbons that combine a high surface area and a porosity made up of narrow micropores (high energy density) with a particle structure that will ensure short diffusional distances $(<100 \mathrm{~nm}$ ). The fabrication of nanometer-sized porous carbon particles of $<200 \mathrm{~nm}$ would constitute an important step in this direction. Porous carbon nanosheets would be a rational option given that their $2 \mathrm{D}$ morphology implies short diffusion distances. Graphene is the most popular example of a 2D carbon nanostructure. However, it has been observed that graphene nanosheets tend to aggregate (self-restacking) during the preparation of the electrode, which results in a substantial loss of active surface area that reduces its electrochemical performance. ${ }^{13}$ Therefore, the fabrication of nonaggregating porous carbon nanosheets presents an important challenge. In this respect, we recently reported a simple method for fabricating interconnected microporous carbon nanosheets that demonstrated a high power-handling ability. ${ }^{14}$ The present paper focuses on the possibilities offered by hollow carbon particles (capsules) with a porous shell enveloping a macroporous core. The 
advantage of this structure is that it can be assimilated to a curved porous carbon nanosheet. What is more, due to the fact that these particles have a curved morphology, it is clear that the stacking of the carbon sheets can be prevented.

Herein we present a procedure for the fabrication of carbon capsules that combine several important properties for application as EDLC electrodes: a) a high surface area and a pore volume made up of uniform pores (mesopores or micropores, depending on the synthesis method adopted), b) a porosity confined within a thin curved layer with a thickness $<100 \mathrm{~nm}, \mathrm{c}$ ) a large number of nitrogen functional groups and d) a carbon framework containing graphitic domains that enhance the electronic conductivity. The carbon capsules were synthesized by means of a nanocasting approach based on silica particles with a solid core and a mesoporous shell as template. More importantly, we used a nitrogen-rich substance (pyrrole) as carbon precursor, which gives rise to a carbon material with a large number of nitrogen groups. An additional chemical activation step with $\mathrm{KOH}$ was used to generate a microporous network. The synthesis method is illustrated in Scheme 1.

\section{Experimental section}

\section{Preparation of mesoporous N-doped carbon capsules}

The $\mathrm{N}$-doped carbon capsules with a hollow core and a mesoporous shell were produced by using template silica particles composed of a solid core and a mesoporous shell (SCMS) as sacrificial and pyrrole monomer (Aldrich, 99\%) as the $\mathrm{N}$-containing carbon precursor. The SCMS particles used as template were 
synthesized as reported by Unger et al. ${ }^{15}$ The procedure for the synthesis of the carbon capsules consisted of the following steps: a) the SCMS particles were impregnated by the drop-wise addition of a $2 \mathrm{M} \mathrm{FeCl}_{3}$ ethanol solution (around $0.27 \mathrm{~g} \mathrm{FeCl}_{3} / \mathrm{g}$ silica), b) the impregnated sample was exposed to pyrrole vapors at $25^{\circ} \mathrm{C}$ for $22 \mathrm{~h}$ in a closed vessel, c) the dark solid thus obtained was heated under $\mathrm{N}_{2}$ up to $850^{\circ} \mathrm{C}\left(3^{\circ} \mathrm{C} \min ^{-1}\right)$ for $1 \mathrm{~h}$. Finally, the carbonized composite was treated with hydrofluoric acid to dissolve the silica framework. The carbon residue was collected by filtration, washed with distilled water, and dried at $120^{\circ} \mathrm{C}$ for several hours. This type of carbon capsule with nitrogen functionalities has been designated as N-CC. For comparison purposes, undoped carbon capsules were prepared by using furfuryl alcohol as carbon precursor according to the conventional infiltration procedure reported elsewhere. ${ }^{16,17}$ This sample has been denoted as CC.

The activation of the templated mesoporous capsules was carried out with $\mathrm{KOH}$. For this purpose we used carbon capsules prepared at carbonization temperatures of $600{ }^{\circ} \mathrm{C}$ and $700{ }^{\circ} \mathrm{C}$. In these experiments, a $6 \mathrm{M}$ aqueous solution of $\mathrm{KOH}$ was added drop-wise to the carbon sample until a $\mathrm{KOH} /$ carbon weight ratio of 1 was attained. The impregnated sample was dried under vacuum at $50{ }^{\circ} \mathrm{C}$ for several hours and then it was heated up to $800{ }^{\circ} \mathrm{C}\left(3^{\circ} \mathrm{C}\right.$ $\min ^{-1}$ ) for $1 \mathrm{~h}$ under $\mathrm{N}_{2}$. Finally, the solid residue was washed three times with $\mathrm{HCl}(10 \%)$ to remove the potassium compounds and distilled water. The carbon particles were collected by centrifugation and dried at $120^{\circ} \mathrm{C}$ for several hours. These activated carbon capsules have been denoted as $N-C C A-X, X$ being the carbonization temperature in ${ }^{\circ} \mathrm{C}\left(600^{\circ} \mathrm{C}\right.$ or $\left.700{ }^{\circ} \mathrm{C}\right)$.

\section{Characterization of materials}


The morphology of the powders was examined by scanning (SEM, Zeiss DSM 942) and transmission (HRTEM, JEOL (JEM 2100-F)) electron microscopy. Nitrogen sorption isotherms were performed at $-196{ }^{\circ} \mathrm{C}$ in a Micromeritics ASAP 2020 volumetric adsorption system. The Brunauer-Emmett-Teller (BET) surface area was deduced from an analysis of the isotherm in the relative pressure range of $0.04-0.20$. The total pore volume was calculated from the amount of nitrogen adsorbed at a relative pressure of 0.90 . The mesopore size distribution was calculated by means of the Kruk-Jaroniec-Sayari method. ${ }^{18}$ The primary mesopore volume $\left(\mathrm{V}_{\mathrm{m}}\right)$ and external surface area $\left(\mathrm{S}_{\text {ext }}\right)$ were estimated using the $\alpha_{s}$-plot method. The reference adsorption data used for the $\alpha_{s}$ analysis of the silica and carbon samples correspond to a macroporous silica sample, ${ }^{19}$ and a non-graphitized carbon black sample, ${ }^{20}$ respectively. The micropore volume $\left(\mathrm{V}_{\mathrm{mi}}\right)$, the micropore surface area $\left(\mathrm{S}_{\mathrm{mi}}\right)$ and the micropore size distributions were determined by means of the Quenched-Solid Density Functional Theory (QSDFT) method applied to the nitrogen adsorption data and assuming a slit pore model.

The thermogravimetric analysis was performed on a Cl Electronics system. The Raman spectra were recorded on a Horiva (LabRamHR-800) spectrometer. The source of radiation was a laser operating at a wavelength of $514 \mathrm{~nm}$ and at a power of $25 \mathrm{~mW}$. X-ray photoelectron spectroscopy (XPS) was performed on a Specs spectrometer, using Mg Ka $(1253.6 \mathrm{eV})$ radiation from a double anode at 150 W. X-ray diffraction (XRD) patterns were obtained on a Siemens D5000 instrument operating at $40 \mathrm{kV}$ and $20 \mathrm{~mA}$ and using $\mathrm{Cu}$ Ka radiation $(\lambda=0.15406$ $\mathrm{nm})$. 
The electrical conductivity of the carbon materials was determined by means of a four-probe method. With the home-made apparatus employed for these measurements it was possible to determine the conductivity and packing density simultaneously.

\section{Electrochemical measurements}

The electrodes were prepared by mixing $85 \mathrm{wt} \%$ of active material, $10 \mathrm{wt} \%$ of polytetrafluoroethylene (PTFE) binder (Aldrich, $60 \mathrm{wt} \%$ suspension in water) and 5 wt $\%$ of the conductive additive Super C65 (Timcall company). The electrochemical measurements were performed in two- and three electrode (2E and $3 \mathrm{E}$, respectively) Swagelok-type cells. Electrochemical capacitors were constructed using two carbon electrodes of comparable mass and thickness, electrically isolated by a glassy fibrous separator. Stainless steel current collectors were used with $1 \mathrm{M} \mathrm{TEABF}_{4} /$ acetonitrile and gold current collectors were used with $1 \mathrm{M} \mathrm{H}_{2} \mathrm{SO}_{4}$ as aqueous electrolyte. The electrochemical characterization was performed using a computer controlled potentiostat (Biologic VMP3 multichannel generator). Cyclic voltammetry was conducted between 0 and $2 \mathrm{~V}$ in the organic medium and between 0 and $1.1 \mathrm{~V}$ in the aqueous medium at sweep rates ranging from 1 to $500 \mathrm{mV} \mathrm{s}^{-1}$. The specific gravimetric capacitance of a single-electrode $\left(\mathrm{F} \mathrm{g}^{-1}\right)$ evaluated from the data obtained in the 2-cell configuration was calculated from the area of the voltammograms by means of the formula

$$
C_{s p}=\frac{\phi I d V}{v \cdot m \cdot \Delta V}
$$


where $i=$ current $(\mathrm{A}), v=$ scan rate $\left(\mathrm{V} \mathrm{s}^{-1}\right), \mathbf{\Lambda} V=$ voltage window $(\mathrm{V})$ and $m=$ mass (grams) of carbon material in the working electrode.

Galvanostatic charge/discharge cycling was also performed in the 0 and $2 \mathrm{~V}$ range in the organic medium and in the 0 and $0.8 \mathrm{~V}$ range in the aqueous medium at current densities in the $0.1-100 \mathrm{~A} \mathrm{~g}^{-1}$ range based on the active mass of a single electrode. The specific gravimetric capacitance of a single electrode $\left(\mathrm{F} \mathrm{g}^{-1}\right)$ determined from the galvanostatic cycles was calculated by means of the formula

$C_{s p}=\frac{2 I}{\left(d V / V_{d t}\right) \cdot m}$

where $d V / d t=$ slope of the discharge curve $\left(\mathrm{V} \mathrm{s}^{-1}\right)$.

Experiments were also carried out in three-electrode cells, using a graphite rod as counter electrode and $\mathrm{Hg} / \mathrm{Hg}_{2} \mathrm{SO}_{4}$ (SME) as the reference electrode. The corresponding specific gravimetric capacitance $\left(\mathrm{F} \mathrm{g}^{-1}\right)$ was also evaluated.

\section{Results and Discussion}

Structural and chemical properties of mesoporous $\mathrm{N}$-doped carbon capsules

The morphology and structure of the $\mathrm{N}-\mathrm{CC}$ carbon were first examined by scanning electron microscopy (SEM) and transmission electron microscopy (TEM) (Figure 1). The SEM image in Figure 1a shows that this sample consists of spherical carbon particles with a uniform diameter of $575 \pm 40 \mathrm{~nm}$. The 
hollow structure of these particles is confirmed by the TEM image in Figure $1 \mathrm{~b}$. The high-magnification TEM image in Figure 1c reveals that the diameter of the central macroporous core is around $330 \pm 40 \mathrm{~nm}$ and that the porous shell has a thickness of around 50-55 nm. The porosity of the carbon shell was investigated by means of nitrogen physisorption analysis. The nitrogen sorption isotherms of the N-CC sample and the silica-carbon composite obtained after carbonization are depicted in Figure 1d. It can be seen that the silica-carbon composite has poor textural properties with low nitrogen uptakes and a BET surface area of $\sim 100 \mathrm{~m}^{2} \mathrm{~g}^{-1}$ (see Table 1). However, once the silica is removed, the resulting $\mathrm{N}-\mathrm{CC}$ carbon exhibits a well-developed porosity, as is evidenced from the corresponding $\mathrm{N}_{2}$ sorption isotherm (Figure 1d). This isotherm profile exhibits a well-defined capillary condensation step which is typical of mesoporous materials (Type IV isotherm), indicating that the porosity is mainly made up of mesopores. This is confirmed by the pore size distribution in Figure $1 d$ (inset), which reveals that the porosity of the N-CC sample is made up of mesopores centered at $3.8 \mathrm{~nm}$. The textural properties of the $\mathrm{N}$-doped carbon capsules are summarized in Table 1, along with those of the silica/carbon composite (C-S) and undoped carbon capsules (CC). These results show that the N-CC capsules have large BET surface areas and high pore volumes of $1590 \mathrm{~m}^{2} \mathrm{~g}^{-1}$ and $1.46 \mathrm{~cm}^{3} \mathrm{~g}^{-1}$ respectively. These textural properties are similar to those of undoped capsules (CC), which have a BET surface area of $1660 \mathrm{~m}^{2}$ $\mathrm{g}^{-1}$ and a pore volume of $1.61 \mathrm{~cm}^{3} \mathrm{~g}^{-1}$. The porosity of the carbon capsules $(\mathrm{N}-$ CC and CC samples) is made up almost exclusively of mesopores, as is deduced by means of the $\alpha_{s}$-plot method applied to the $N_{2}$ adsorption branch, 
with the micropores representing only $<5 \%$ of the total pore volume (see Table 1).

The microstructure of the carbons was investigated by X-ray diffraction (XRD) and Raman spectroscopy (Figure 2). The XRD patterns in Figure 2a show that, while the $\mathrm{CC}$ sample exhibits a broad band typical of amorphous carbon at around the $2 \theta \sim 20-30^{\circ}$ region, the XRD spectra of the $\mathrm{N}-\mathrm{CC}$ carbon exhibits a sharp peak at around $2 \theta=26^{\circ}$, which can be assigned to the (002) diffraction of graphitic carbon. This peak is superimposed upon the broad band corresponding to amorphous carbon, which suggests the presence of a certain number of graphitic domains embedded inside an amorphous matrix. The presence of graphitic and amorphous domains was further confirmed by Raman spectroscopy performed in randomly selected regions revealing amorphous or graphitic structural properties (Figure 2b). While the first-order Raman spectrum of amorphous carbon (black line) is composed of two broad overlapping bands ( $D$ and $G$ ), the graphitic regions exhibit a spectrum (red line) composed of a high-intensity sharp $G$ band at $1575 \mathrm{~cm}^{-1}$ associated to the $E_{2 g 2}$ vibrational mode of $\mathrm{sp}^{2}$ bonded carbon atoms in the graphene sheets and a weak $\mathrm{D}$ band at $1350 \mathrm{~cm}^{-1}$ related to imperfections in the graphitic sp $\mathrm{sparbon}^{2}$ structures. The presence of graphitic domains embedded in the amorphous carbon framework is due to the fact that the iron nanoparticles generated during the carbonization act as a graphitization catalyst that converts some of the amorphous carbon into graphitic nanostructures. ${ }^{21-25}$ The amount of graphitic carbon in the N-CC sample was evaluated by means of thermogravimetric analysis (Figure 2c). It can be seen that the weight loss plot shows two steps at $420^{\circ} \mathrm{C}$ and $580^{\circ} \mathrm{C}$, which can be ascribed to the amorphous and graphitic carbon respectively. On 
the basis of this information, the content of graphitic carbon in N-CC is estimated to be $\sim 10$ wt $\%$. The presence of these graphitic domains notably improves the electrical conductivity of the carbon materials. This parameter was determined by means of a four-probe method by pressing the powders at 7.1 MPa. The results obtained show that the N-CC sample with graphitic carbon has an electrical conductivity of $0.22 \mathrm{~S} \mathrm{~cm}^{-1}$, which is notably superior to that of the CC carbon capsules $\left(0.08 \mathrm{~S} \mathrm{~cm}^{-1}\right)$.

The nitrogen content of the $\mathrm{N}-\mathrm{CC}$ sample as determined by elemental analysis is $5.88 \mathrm{wt} \%$ (Table 1). The chemical nature of the nitrogen groups was investigated by means of XPS measurements (Figure 2d). The high-resolution $\mathrm{N}$ 1s XPS spectrum for the $\mathrm{N}-\mathrm{CC}$ sample can be deconvoluted in two main peaks at 398.6 and $400.9 \mathrm{eV}$ that are assigned to pyridinic- $\mathrm{N}(40.4 \%)$ and quaternary-N (53.7\%) respectively, and a minor peak at $402.7 \mathrm{eV}$, which can be

attributed to pyridine-N-oxides $(5.9 \%)$. 26,27 The N/C atomic ratios corresponding to the bulk (0.064) and the surface (0.068) are similar, indicating that the nitrogen functionalities are homogeneously distributed throughout the particles.

\section{Microporous N-doped Carbon Capsules}

The surface area and the micropore volume of the templated carbon capsules were increased by using a well-established chemical activation method with $\mathrm{KOH}$. The TEM images in Figures $3 \mathrm{a}$ and $3 \mathrm{~b}$ reveal that the activated carbon particles retain the hollow structure and spherical morphology. However, chemical activation produces an important reduction in the diameter of the activated carbon capsules from $575 \pm 40$ to $310 \pm 30 \mathrm{~nm}$, although by 
contrast, the thickness of the shell hardly changes, $\sim 50 \mathrm{~nm}$. The HRTEM microphotograph in Figure 3c, which was taken at the edge of a capsule, reveals that their porosity consists of a microporous network with randomly oriented narrow micropores. This is confirmed by the nitrogen physisorption measurements of the activated materials, which show that chemical activation of the mesoporous carbon capsules causes a drastic change to their porous structure from a mesoporous network to a porosity made up almost exclusively of micropores. The nitrogen sorption isotherms and the pore size distributions in Figure 4 clearly show the change in the type of porosity. Thus, it can be seen that the shape of the isotherms changes from type IV characteristic of mesoporous materials to type I typical of microporous materials. On the other hand, the pore size distributions represented in Figures $4 \mathrm{~b}$ and $4 \mathrm{~d}$ reveal that, while the un-activated templated carbons (N-CC-600 and N-CC-700) have a porosity made up essentially of mesopores, that of the $\mathrm{KOH}$ activated samples (N-CCA-600 and N-CCA-700) is a porosity made up of two pore systems in the micropore range with sizes centered at $0.85 \mathrm{~nm}$ and $1.40 \mathrm{~nm}$. Moreover, the BET surface area and the micropore volumes of the activated samples have significantly increased up to $2470 \mathrm{~m}^{2} \mathrm{~g}^{-1}$ and $1.02 \mathrm{~cm}^{3} \mathrm{~g}^{-1}$ for the N-CCA-600 sample and $2080 \mathrm{~m}^{2} \mathrm{~g}^{-1}$ and $0.80 \mathrm{~cm}^{3} \mathrm{~g}^{-1}$ for the N-CCA-700 sample respectively (see Table 2).

Chemical activation has led to a reduction in the nitrogen content down to $\sim 2 \mathrm{wt} \%$ as determined by elemental analysis (Table 2). The chemical nature of the nitrogen groups in the activated sample N-CCA-600 was investigated by XPS. Similarly to the N-doped mesoporous carbon particles (Figure 2d), the nitrogen present in the activated samples is distributed between pyridinic- $\mathrm{N}$ 
(398.6 eV, $25.5 \%)$, quaternary- $\mathrm{N}(400.8 \mathrm{eV}, 67.2 \%)$ and pyridinic-N-oxide (402.8 eV, $7.3 \%)$ as can be seen from the high-resolution N 1s XPS spectrum in Figure 3d.

\section{Electrochemical performance}

A three-electrode configuration was first used to investigate pseudocapacitance effects associated with the nitrogen/oxygen-containing functional groups. This study was performed in $1 \mathrm{M} \mathrm{H}_{2} \mathrm{SO}_{4}$ and we analyzed the $\mathrm{N}$-doped samples (i.e. $\mathrm{N}-\mathrm{CC}$ and $\mathrm{N}-\mathrm{CCA}-600$ ) and undoped $\mathrm{CC}$ carbon. Figure 5 shows the corresponding three-electrode cyclic voltammograms obtained at a sweep rate of $2 \mathrm{mV} \mathrm{s}^{-1}$ over the maximum stability potential window. For the CC sample, a well-defined peak appears at $-0.1 \mathrm{~V}\left(\mathrm{vs}\right.$. $\left.\mathrm{Hg} / \mathrm{Hg}_{2} \mathrm{SO}_{4}\right)$ during positive polarization and at $-0.2 \mathrm{~V}\left(\mathrm{vs} . \mathrm{Hg} / \mathrm{Hg}_{2} \mathrm{SO}_{4}\right)$ during negative polarization, which is assigned to redox reactions involving the quinone/hydroquinone pair. ${ }^{28-30}$ On the other hand, in the case of the N-doped N-CC carbon a wide hump is observed from 0.6 to $0.3 \mathrm{~V} v \mathrm{vs} . \mathrm{Hg} / \mathrm{Hg}_{2} \mathrm{SO}_{4}$ in both the anodic and cathodic sweeps. This broad hump is the result of the superimposition of several redox reactions involving the pyridinic groups (found by XPS $)^{31,32}$ and the oxygen functionalities $(\sim 10$ $\mathrm{wt} \% \mathrm{O}$ ). It can be seen that the surface-area normalized capacitance of $\mathrm{N}-\mathrm{CC}$ is significantly greater than for the undoped CC carbon (Figure 5). A comparison of the $\mathrm{CV}$ curves of the $\mathrm{CC}$ and $\mathrm{N}-\mathrm{CC}$ samples clearly reveals the additional contribution of the N/O-groups to capacitance (see Figure $5 b$ ). In the case of the $\mathrm{N}-\mathrm{CCA}-600$ activated sample, the results in Figure 5 suggest that their capacitive behavior is mainly due to the formation of the double-layer with a small contribution by pseudocapacitance. It is worth noting here that $\mathrm{N}$-doping 
has up-shifted carbon oxidation by $0.1 \mathrm{~V}$, an advantage that we have already observed in other $\mathrm{N}$-doped carbons. ${ }^{29,33}$

The electrochemical behavior of the $\mathrm{N}$-doped carbon capsules was also examined in a two-electrode cell system. Taking into account the maximum stability window previously measured in the three-electrode setup (Figure 5), a cell voltage of $1.1 \mathrm{~V}$ was applied in the symmetric supercapacitor. The cyclic voltammograms for the $\mathrm{N}$-doped capsules display a clear faradic hump at cell voltages $<0.4 \mathrm{~V}$ (see Figure 6a). This feature is maintained up to $200-500 \mathrm{mV}$ $\mathrm{s}^{-1}$, indicating a fast ion and electron transport, which is coherent with the relatively good electronic conductivity of the material and the short ion-diffusion paths $(<30 \mathrm{~nm})$. In contrast, in the case of the activated samples (i.e. N-CCA600 and N-CCA-700), the curves display a square shape (Figure $6 \mathrm{~b}$ and c), suggesting only a small contribution by faradaic redox reactions. This shape is preserved up to $500 \mathrm{mV} \mathrm{s}^{-1}$, which indicates a fast charge propagation in spite of the microporous character of these samples. The above results for the templated carbon capsules confirm the effectiveness of the curved shell morphology in the enhancement of ion-transport.

In order to evaluate the energy and power characteristics of the synthesized samples, galvanostatic charge/discharges (CD) cyclic experiments were performed. Interestingly, the CD profiles shown in Figure $6 \mathrm{~d}$ corresponding to the $\mathrm{N}-\mathrm{CC}$ sample, do not exhibit a constant slope. This is a consequence of the pseudocapacitance effects associated with $\mathrm{N}$-groups, confirming the results derived from the CV curves (Figure 5a). Nevertheless, these CD curves are highly symmetrical, suggesting the reversibility of the redox reactions (Coulombic efficiency $>98 \%$ ). On the contrary, in the case of the N-CCA-700 
and N-CCA-600 samples, the CD voltage profiles show a constant slope reflecting their double-layer capacitor behavior. As shown in the inset of Figure $6 \mathrm{~d}$, the mesoporous carbon capsule-based supercapacitor exhibits a very low voltage drop even at a high current density of $10 \mathrm{~A} \mathrm{~g}^{-1}$, which evidences a small equivalent series resistance (ESR) and suggests that these materials are capable of an excellent rate performance. This is confirmed by the results in Figure 7 , which show the variation in specific capacitance versus the current density. It can be seen that in the case of the N-CC sample, specific capacitance varies from $\sim 236 \mathrm{~F} \mathrm{~g}^{-1}\left(0.1 \mathrm{~A} \mathrm{~g}^{-1}\right)$ down to $\sim 170 \mathrm{~F} \mathrm{~g}^{-1}$ at a current density as high as $80 \mathrm{~A} \mathrm{~g}^{-1}$. This variation means that capacitance retention is as high as $72 \%$ at $80 \mathrm{~A} \mathrm{~g}^{-1}$, which confirms the better performance of these materials compared to other nitrogen doped materials found in the literature (see Figure S1 in SI). ${ }^{12,34-39}$ In contrast, although the activated carbon capsules exhibit high values of specific capacitance at low discharge rates $\left(232 \mathrm{~F} \mathrm{~g}^{-1}\right.$ and $240 \mathrm{~F} \mathrm{~g}^{-1}$ for $\mathrm{N}-\mathrm{CCA}-700$ and $\mathrm{N}-\mathrm{CCA}-600$, respectively at $0.1 \mathrm{~A} \mathrm{~g}^{-1}$ ) owing to their large surface area and the abundant micropores, they display worse performance at high current densities (capacitance retention of around 62-64\% at $80 \mathrm{~A} \mathrm{~g}^{-1}$ see inset in Figure 7). This can be attributed to the presence of numerous narrow micropores. At this point, it should be noted that the undoped carbon capsules $\mathrm{CC}$ exhibit, in relation to the N-CC sample, a lower specific capacitance over the whole range of discharge currents and a higher capacitance fading with the increase of discharge current ( 40\%) as illustrated in Figure 7. In addition, comparison of the surface-area normalized capacitance measured at $0.1 \mathrm{~A} \mathrm{~g}^{-1}$ for the different samples reveals that the $\mathrm{N}$-doped capsules $(\mathrm{N}-\mathrm{CC})$ have a notably superior value, i.e. $14.8 \mu \mathrm{F} \mathrm{cm}{ }^{-2}$, than that of 
the undoped carbon capsules $\left(11.9 \mu \mathrm{F} \mathrm{cm}^{-2}\right)$ and the activated carbon capsules (11.1 $\mu \mathrm{F} \mathrm{cm}^{-2}$ for N-CCA-700 and $9.7 \mu \mathrm{F} \mathrm{cm}^{-2}$ for N-CCA-600). These results clearly indicate that the capacitive behavior of these samples is very much dependent on the presence of N-groups. As is common for many nanomaterials, the packing density of these capsules is low, i.e. $0.29 \mathrm{~g} \mathrm{~cm}^{-3}$ for $\mathrm{N}-\mathrm{CC}$ and $0.26 \mathrm{~g} \mathrm{~cm}^{-3}$ for N-CCA-700 and N-CCA-600. This leads to volumetric specific capacitances of $60-68 \mathrm{~F} \mathrm{~cm}^{-3}$, in the range of those of activated carbons. $^{40}$

The energy and power characteristics of the different samples are compared in the Ragone plot (Figure 8a). The maximum amount ofenergy stored by the $\mathrm{N}$ CC-based supercapacitor is $\sim 10 \mathrm{Wh} \mathrm{kg}^{-1}$ and the maximum specific power is 28 $\mathrm{kW} \mathrm{kg}^{-1}$. Slightly lower values of specific energy are obtained for the activated carbon capsules at low discharge rates. However, at high discharge rates (> 10 $\mathrm{kW} \mathrm{kg}^{-1}$ ), the energy stored at a certain specific power is higher owing to the smaller ESR. The stability of the electrode materials under long-term cycling is important in relation to their practical utilization. This feature was evaluated by applying a discharge current density of $5 \mathrm{~A} \mathrm{~g}^{-1}$ over 10000 cycles and at a cell voltage $=1.1 \mathrm{~V}$. The results displayed in Figure $8 \mathrm{~b}$ for $\mathrm{N}-\mathrm{CC}, \mathrm{N}-\mathrm{CCA}-700$ and $\mathrm{N}-\mathrm{CCA}-600$, reveal that the capacitance losses are as low as $4 \%$ for $\mathrm{N}-\mathrm{CC}$, and $6 \%$ and $7 \%$ for N-CCA-600 and N-CCA-700, respectively, confirming the robustness of these materials even at a large cell voltage of $1.1 \mathrm{~V}$. It is also worth noting that an increase in the energy stored in the device of $\sim 130 \%$ for $\mathrm{N}-\mathrm{CC}$ (maximum energy density at $0.8 \mathrm{~V}$ is $4.3 \mathrm{Wh} \mathrm{kg}^{-1}$ ) and $\sim 120 \%$ for the activated carbon capsules (maximum energy density at $0.8 \mathrm{~V}$ is $4.5 \mathrm{Wh} \mathrm{kg}^{-1}$ for $\mathrm{N}-\mathrm{CCA}-600$ and $4.3 \mathrm{Wh} \mathrm{kg}^{-1}$ for $\mathrm{N}-\mathrm{CCA}-700$ ) is possible without compromising 
long-term stability when the cell voltage is increased from $0.8 \mathrm{~V}$ (the voltage normally used with acid and alkaline electrolytes) to $1.1 \mathrm{~V}$ owing to the dual factor of the increased cell voltage and enhanced specific capacitance resulting from a larger pseudocapacitance contribution over the wider voltage range. The above results show that the $\mathrm{N}$-doped mesoporous carbon capsules have an excellent electrochemical performance in an aqueous electrolyte $\left(1 \mathrm{M}, \mathrm{H}_{2} \mathrm{SO}_{4}\right)$, exhibiting slightly higher energy and power characteristics to those of the activated samples despite their lower surface area, the reason for this being the pseudocapacitive contributions related to the $\mathrm{N}$-groups.

Further electrochemical characterization of the materials was carried out in an organic electrolyte $1 \mathrm{M} \mathrm{TEABF}_{4} / \mathrm{AN}$ using a two-electrode cell system. Since the charge storage mechanism in this case is based on the formation of the electric double-layer, it can be hypothesized that the electrochemical behavior of these samples will depend exclusively on their porous characteristics. This is confirmed by the cyclic voltammograms obtained for the templated (Figure 9a) and activated samples (Figures 9b and 9c), which display a perfect squareshape, confirming that a double-layer storage mechanism is operating for both the meso- and microporous capsules. This square shape is maintained even at a high scan rate of $500 \mathrm{mV} \mathrm{s}^{-1}$, indicating low ion-transport resistances. Worthy of special note is the behavior of the activated samples N-CCA-600 and NCCA-700 which, despite being microporous, exhibit a capacitance retention of $75 \%$ at $500 \mathrm{mV} \mathrm{s}^{-1}$ (see Figure $9 \mathrm{~d}$ ). The increase in surface area caused by the chemical activation step leads to a rise in specific capacitance from $96 \mathrm{~F} \mathrm{~g}^{-1}$ (for $\mathrm{N}-\mathrm{CC}$ ) to $146 \mathrm{~F} \mathrm{~g}^{-1}$ (for N-CCA-600) and $123 \mathrm{~F} \mathrm{~g}^{-1}$ (for N-CCA-700) at a scan rate of $1 \mathrm{mV} \mathrm{s}^{-1}$. Galvanostatic charge-discharge cycling experiments further 
confirm the excellent rate capability of these materials. As can be seen in Figure 10a, a small IR drop is observed at a current density of $10 \mathrm{~A} \mathrm{~g}^{-1}$, even in the case of the microporous activated carbon capsules. Figure 10b shows the variation of specific capacitance with the current density for the different materials. As no pseudocapacitance phenomena are registered in the organic electrolyte, the specific capacitance correlates directly with the textural properties. Thus, the sample with the highest surface area, (i.e. N-CCA-600), possesses as well the highest capacitance, $141 \mathrm{~F} \mathrm{~g}^{-1}$. Even more remarkable is its capacitance retention, which is as high as $93 \%$ at an ultra-high rate of $100 \mathrm{~A}$ $\mathrm{g}^{-1}$. Furthermore, as shown in Figure 10b, for the microporous carbon capsules, the specific capacitance remains almost constant despite a 10-fold increase in current density, from 10 to $100 \mathrm{~A} \mathrm{~g}^{-1}$. Thus, the microporous carbon capsules exhibit specific capacitances of $100-130 \mathrm{~F} \mathrm{~g}^{-1}$ at $100 \mathrm{~A} \mathrm{~g}^{-1}$, values comparable to those of highly porous nanosheets recently developed in our group. ${ }^{14}$ The rate capability of the present materials is also remarkable compared to other carbon/graphene nanosheets. ${ }^{41-43}$ The energy and power characteristics of the different carbon capsules are compared in the Ragone plot in Figure 10c. The $\mathrm{N}-\mathrm{CCA}-600$ sample exhibits the highest value of energy stored $\left(\sim 17 \mathrm{Wh} \mathrm{kg}^{-1}\right)$ compared to N-CCA-700 (14.2 Wh kg-1) and N-CC $\left(10.6 \mathrm{Wh} \mathrm{kg}^{-1}\right)$ at a specific power of $5 \mathrm{~kW} \mathrm{~kg}^{-1}$. Furthermore, the maximum energy stored by the $\mathrm{N}-\mathrm{CCA}$ 600 -based supercapacitor is $19.5 \mathrm{Wh} \mathrm{kg}^{-1}$ while the maximum specific power is $43.9 \mathrm{~kW} \mathrm{~kg}^{-1}$.

In order to examine long-term stability in organic electrolyte, galvanostatic charge-discharge cycling experiments were carried out at a current density of 5 $\mathrm{A} \mathrm{g}^{-1}$ and at a voltage window of $2 \mathrm{~V}$ over 5000 cycles. The results in Figure $10 \mathrm{~d}$ 
reveal a capacitance loss of only $10 \%$ for all the materials, thereby demonstrating the stability of the electrode materials. At this point, it is important to emphasize the essential role that the hollow morphology plays on electrochemical performance. Indeed, it can be considered that the central macroporous core acts as a buffering reservoir for the electrolyte solution, thereby facilitating the transfer of ions during the charge/discharge experiments and ensuring a good cycling performance. It is to be noted also that the cycling stability of the present materials is higher than that of other carbon materials reported in the literature i.e. graphene, ${ }^{44}$ carbide derived carbon, ${ }^{4}$ mesoporous carbon spheres ${ }^{45}$ and mesoporous carbon capsules. ${ }^{46}$ 


\section{Conclusions}

In summary, we have described a procedure for the fabrication of $\mathrm{N}$-doped hollow carbon microspheres with a large specific surface area, tunable porosity, and good electronic conductivity. The carbon particles were synthesized by means of a nanocasting method using pyrrole as $\mathrm{N}$-rich carbon precursor. They are characterized by a large BET surface area of $\sim 1500 \mathrm{~m}^{2} \mathrm{~g}^{-1}$, a porosity made up of mesopores of size $\sim 4 \mathrm{~nm}$, a high nitrogen content of $\sim 6 \mathrm{wt} \%$ and a capsule morphology that ensures short ion diffusion paths due to the shell morphology (thickness of $\sim 60 \mathrm{~nm}$ ). A chemical activation process with $\mathrm{KOH}$ is used to further enhance the textural properties of the material. In this way, microporous carbon capsules with specific surface areas of up to $2470 \mathrm{~m}^{2} \mathrm{~g}^{-1}$ are obtained. In an aqueous medium $\left(1 \mathrm{M} \mathrm{H}_{2} \mathrm{SO}_{4}\right)$, the mesoporous carbon capsules exhibit the best performance due to the pseudocapacitive contribution of the $\mathrm{N}$-groups. A specific capacitance of $\sim 240 \mathrm{~F} \mathrm{~g}^{-1}$ is obtained at a low discharge rate $\left(0.1 \mathrm{~A} \mathrm{~g}^{-1}\right)$, while a capacitance retention of $72 \%$ is achieved at high discharge rates $\left(80 \mathrm{~A} \mathrm{~g}^{-1}\right)$. On the contrary, in an organic electrolyte $(1 \mathrm{M}$ $\mathrm{TEABF}_{4} / \mathrm{AN}$ ), where the charge storage mechanism is based on the formation of the electric double-layer, the microporous capsules perform better due to the larger specific surface area. Thus, the microporous carbon capsules have a specific capacitance of up to $141 \mathrm{~F} \mathrm{~g}^{-1}\left(0.1 \mathrm{~A} \mathrm{~g} \mathrm{~g}^{-1}\right)$ and an exceptional capacitance retention of $93 \%$ at an ultra-high discharge current density of 100 $A \mathrm{~g}^{-1}$. This outstanding performance is the result of the capsule morphology which provides the material with short diffusion pathways, and an optimized pore system consisting of micropores ideal for efficient charge storage, 
mesopores that serve as highways to and from the micropores, and a macroporous core that functions as a buffering reservoir for the electrolyte solution.

Acknowledgments. This research work was supported by Spanish MINECO (MAT2012-31651). G. A. F. thanks the Ministerio de Economía y Competitividad of Spain for his predoctoral contract and M. S. thanks the Ministerio de Ciencia e Innovación of Spain for her Ramón y Cajal contract. 


\section{Tables and Figures}

Table 1. Textural properties of the silica-carbon composite, undoped carbon capsules and N-doped carbon capsules.

\begin{tabular}{ccccccccc}
\hline \multirow{2}{*}{$\begin{array}{c}\text { Sample } \\
\text { code }\end{array}$} & $\begin{array}{c}\mathrm{S}_{\mathrm{BET}} \\
\left(\mathrm{m}^{2} \mathrm{~g}^{-1}\right)\end{array}$ & $\begin{array}{c}\mathrm{V}_{\mathrm{p}} \\
\left(\mathrm{cm}^{3} \mathrm{~g}^{-1}\right)^{\mathrm{a}}\end{array}$ & $\begin{array}{c}\text { Pore size } \\
(\mathrm{nm})^{\mathrm{b}}\end{array}$ & $\begin{array}{c}\mathrm{a}_{\mathrm{s}} \text {-plot results } \\
\left(\mathrm{cm}^{3} \mathrm{~g}^{-1}\right)^{\mathrm{c}}\end{array}$ & $\begin{array}{c}\mathrm{S}_{\mathrm{ext}} \\
\left(\mathrm{m}^{2} \mathrm{~g}^{-1}\right)^{\mathrm{d}}\end{array}$ & $\begin{array}{c}\mathrm{N} \\
(\mathrm{wt} \%)\end{array}$ & $\begin{array}{c}\mathrm{O} \\
(\mathrm{wt} \%)\end{array}$ \\
\hline S-C & 105 & 0.096 & 1.9 & 0.05 & 12 & - & \\
$\mathrm{CC}$ & 1660 & 1.61 & 3.8 & 1.39 & 124 & - & 8.7 \\
$\mathrm{~N}-\mathrm{CC}$ & 1590 & 1.46 & 3.8 & 1.28 & 92 & 5.88 & 10.04 \\
$\mathrm{~N}-\mathrm{CC}-700$ & 1200 & 1.14 & 3.8 & 0.96 & 116 & - & - \\
N-CC-600 & 1410 & 1.38 & 3.5 & 1.05 & 88.5 & - & - \\
\hline
\end{tabular}

${ }^{a}$ Pore volume determined at $\mathrm{p} / \mathrm{p}_{0}=0.90 .{ }^{\mathrm{b}}$ Maximum of the pore size distribution.

${ }^{c}$ Volume of framework-confined mesopores. ${ }^{d}$ External surface area.

Table 2. Textural properties of the $\mathrm{KOH}$ activated carbon capsules.

\begin{tabular}{ccccccc}
\hline Sample code & $\begin{array}{c}\mathrm{S}_{\mathrm{BET}} \\
\left(\mathrm{m}^{2} \mathrm{~g}^{-1}\right)\end{array}$ & $\begin{array}{c}\mathrm{V}_{\mathrm{p}} \\
\left(\mathrm{cm}^{3} \mathrm{~g}^{-1}\right)^{\mathrm{a}}\end{array}$ & $\begin{array}{c}\mathrm{V}_{\mathrm{mi}} \\
\left(\mathrm{cm}^{3} \mathrm{~g}^{-1}\right)^{\mathrm{b}}\end{array}$ & $\begin{array}{c}\mathrm{V}_{\text {meso }} \\
\left(\mathrm{cm}^{3} \mathrm{~g}^{-1}\right)^{\mathrm{c}}\end{array}$ & $\begin{array}{c}\mathrm{S}_{\mathrm{mi}} \\
\left(\mathrm{m}^{2} \mathrm{~g}^{-1}\right)^{\mathrm{b}}\end{array}$ & $\begin{array}{c}\mathrm{N} \\
(\mathrm{wt} \%)\end{array}$ \\
\hline N-CCA-600 & 2470 & 1.25 & 1.02 & 0.23 & 2150 & 2.09 \\
N-CCA-700 & 2080 & 1.15 & 0.80 & 0.35 & 1740 & 2.45 \\
\hline
\end{tabular}

${ }^{a}$ Pore volume determined at $\mathrm{p} / \mathrm{p}_{0}=0.90 .{ }^{\mathrm{b}}$ Micropore volume and micropore surface area were determined by QSDFT method. ${ }^{\mathrm{C}}$ Mesopore volume obtained by the difference between pore volume $\left(V_{p}\right)$ and micropore volume $\left(V_{m i}\right)$ 


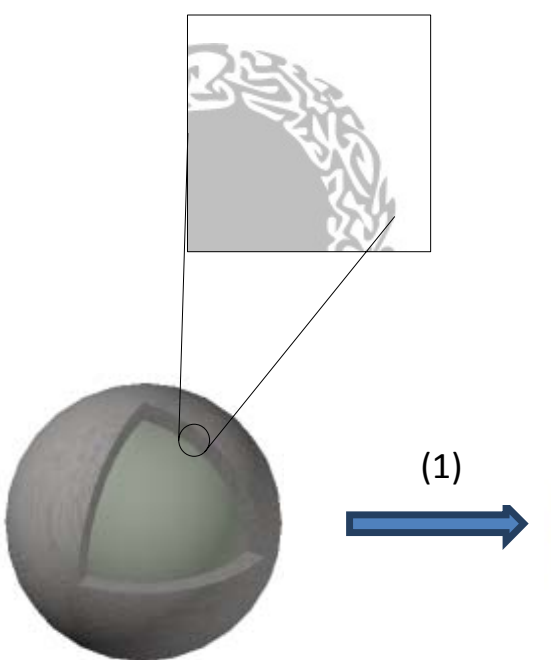

SCMS

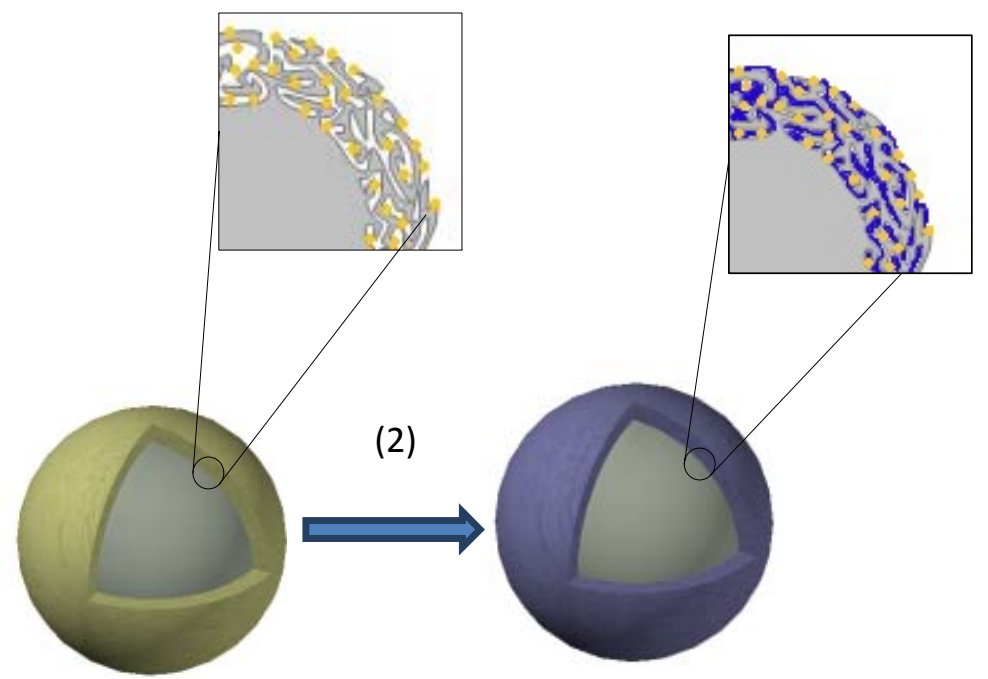

$\mathrm{PPy}-\mathrm{FeCl}_{3}-\mathrm{SCMS}$

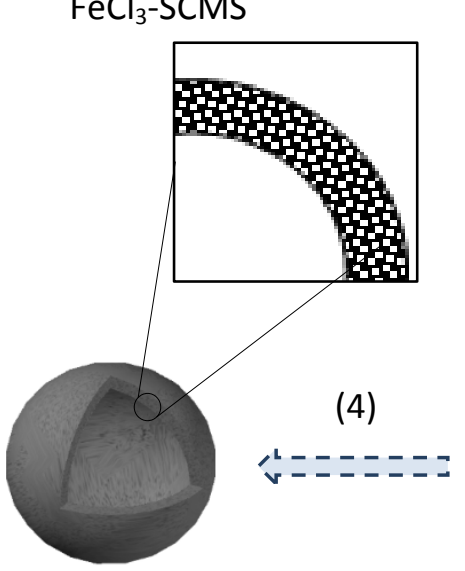

Microporous N-doped carbon capsule

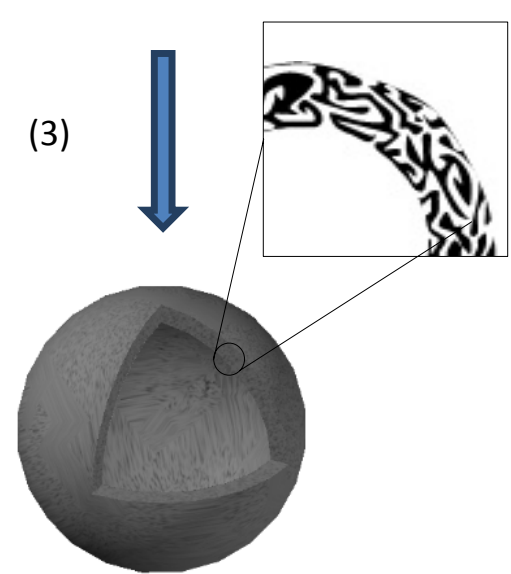

Mesoporous N-doped carbon capsule

Scheme 1. Schematic illustration of the synthesis procedure: (1) $\mathrm{FeCl}_{3}$ infiltration; (2) vapor deposition of pyrrole and polymerization; (3) carbonization and etching of the silica framework and (4) chemical activation. 

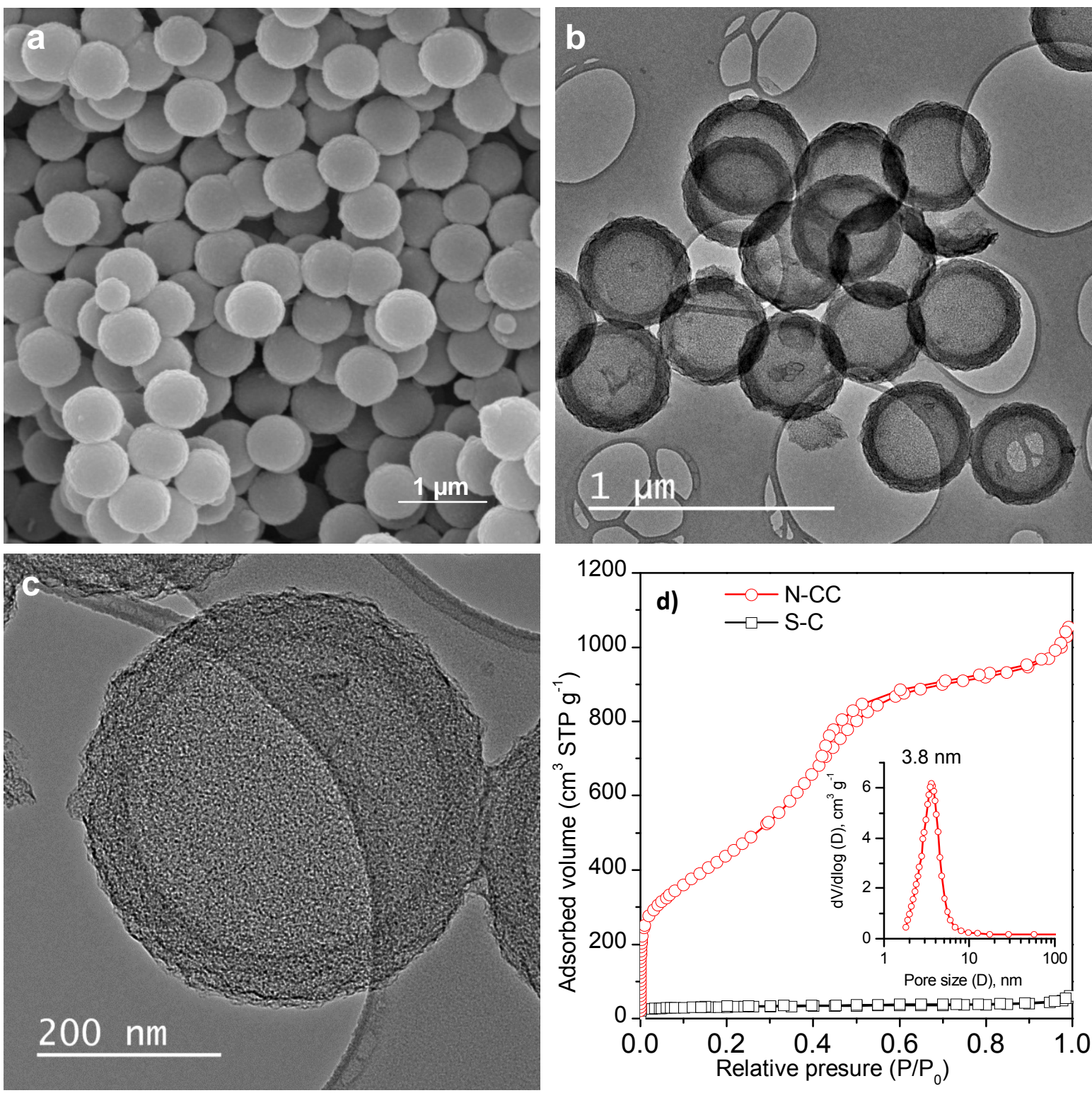

Figure 1. (a) SEM image of the hollow carbon capsules, (b, c) TEM images of the hollow carbon capsules and (d) nitrogen sorption isotherm and pore size distributions (inset) of silica/carbon composites (S-C) and the N-doped carbon capsules $(\mathrm{N}-\mathrm{CC})$ 
a)

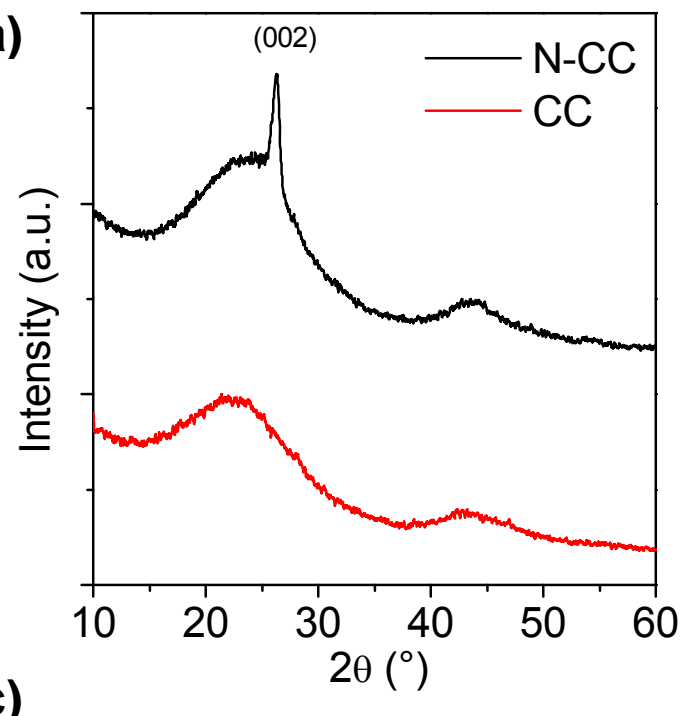

c)

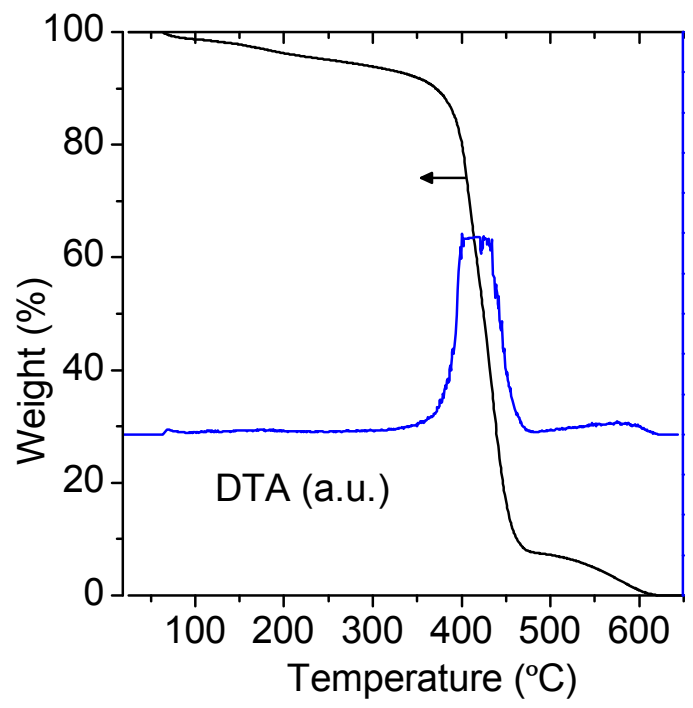

b)

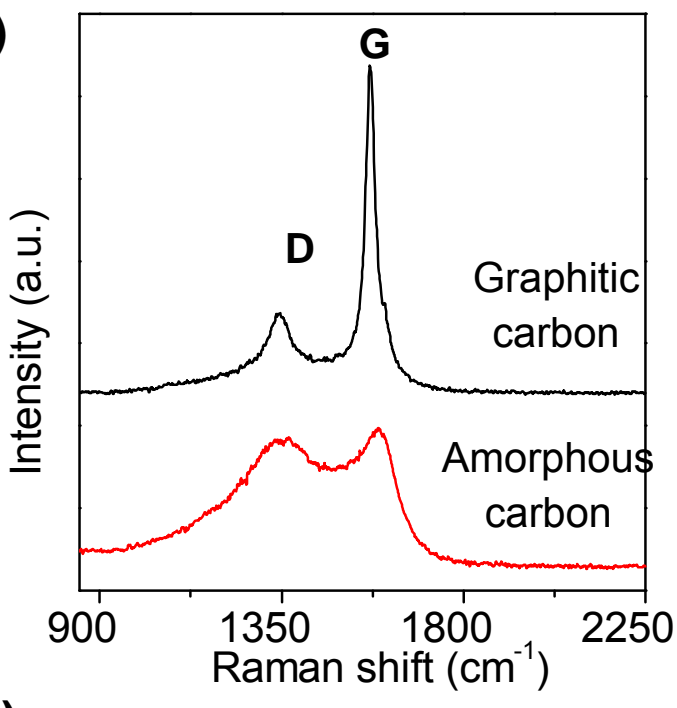

d)

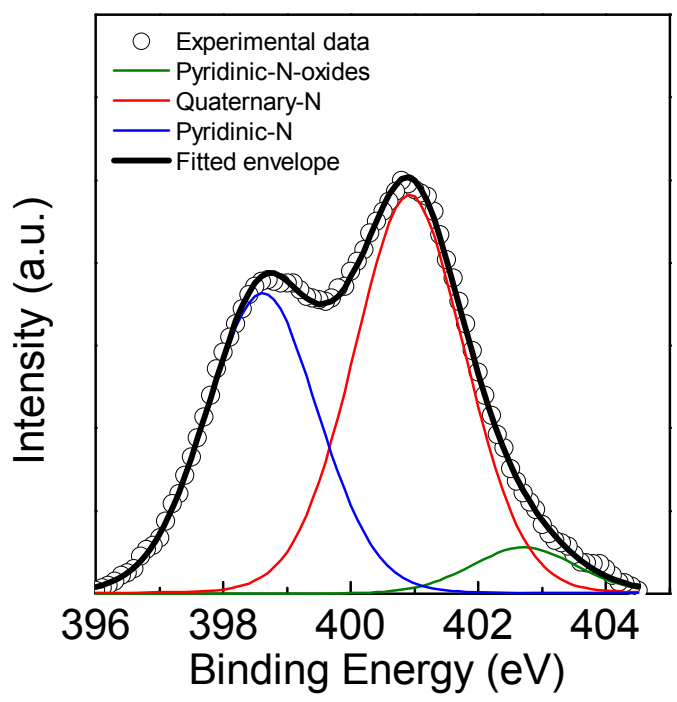

Figure 2. (a) XRD patterns of the N-CC and CC, (b) Raman spectra of amorphous (red line) and graphitic regions (black line) in N-CC, (c) TGA analysis of N-CC and (d) XPS N 1s core level spectrum of N-CC 

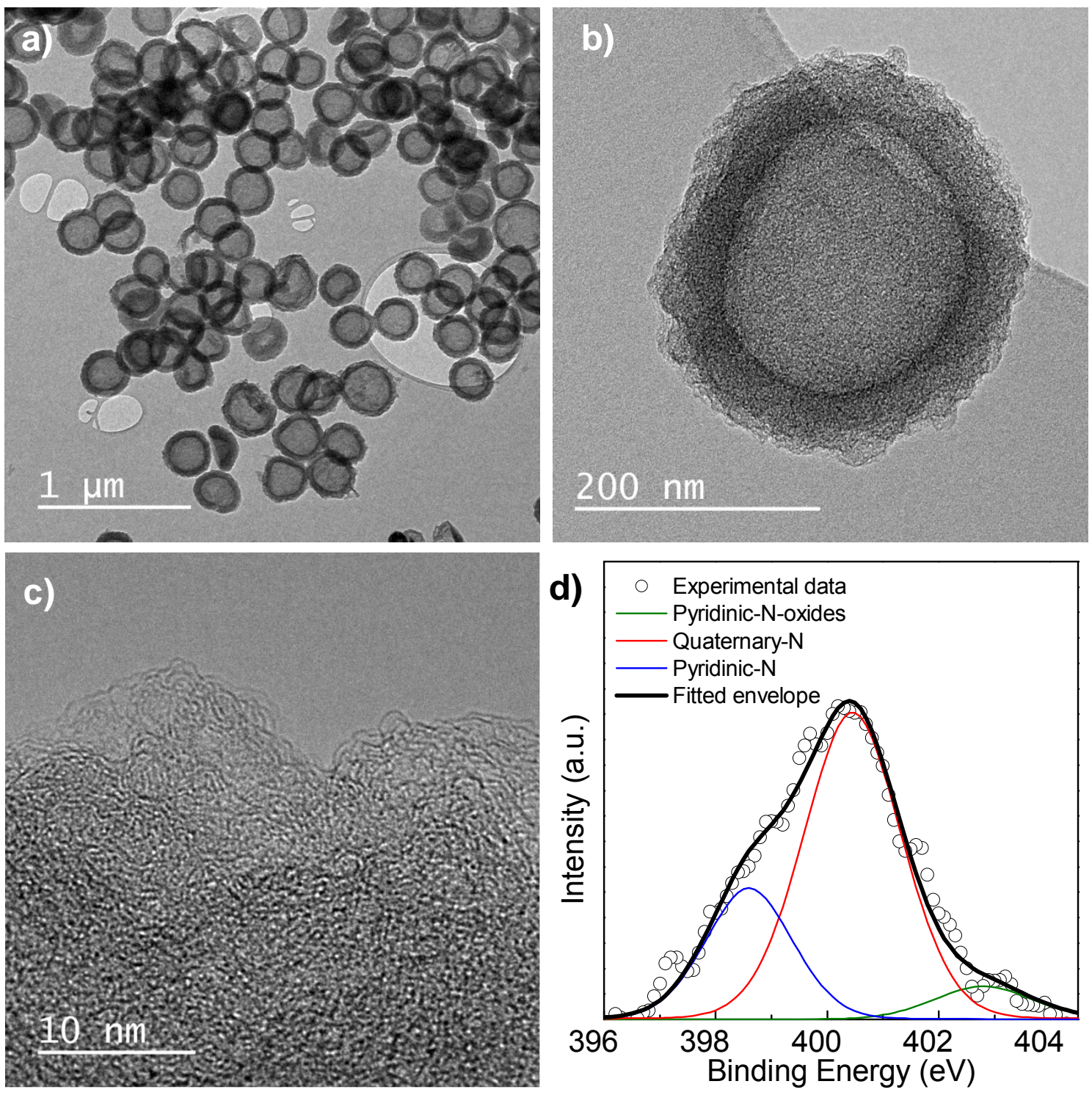

Figure 3. (a,b) TEM images, (c) HRTEM image and (d) XPS N 1s core level spectrum of the chemically activated N-CCA-600 sample. 

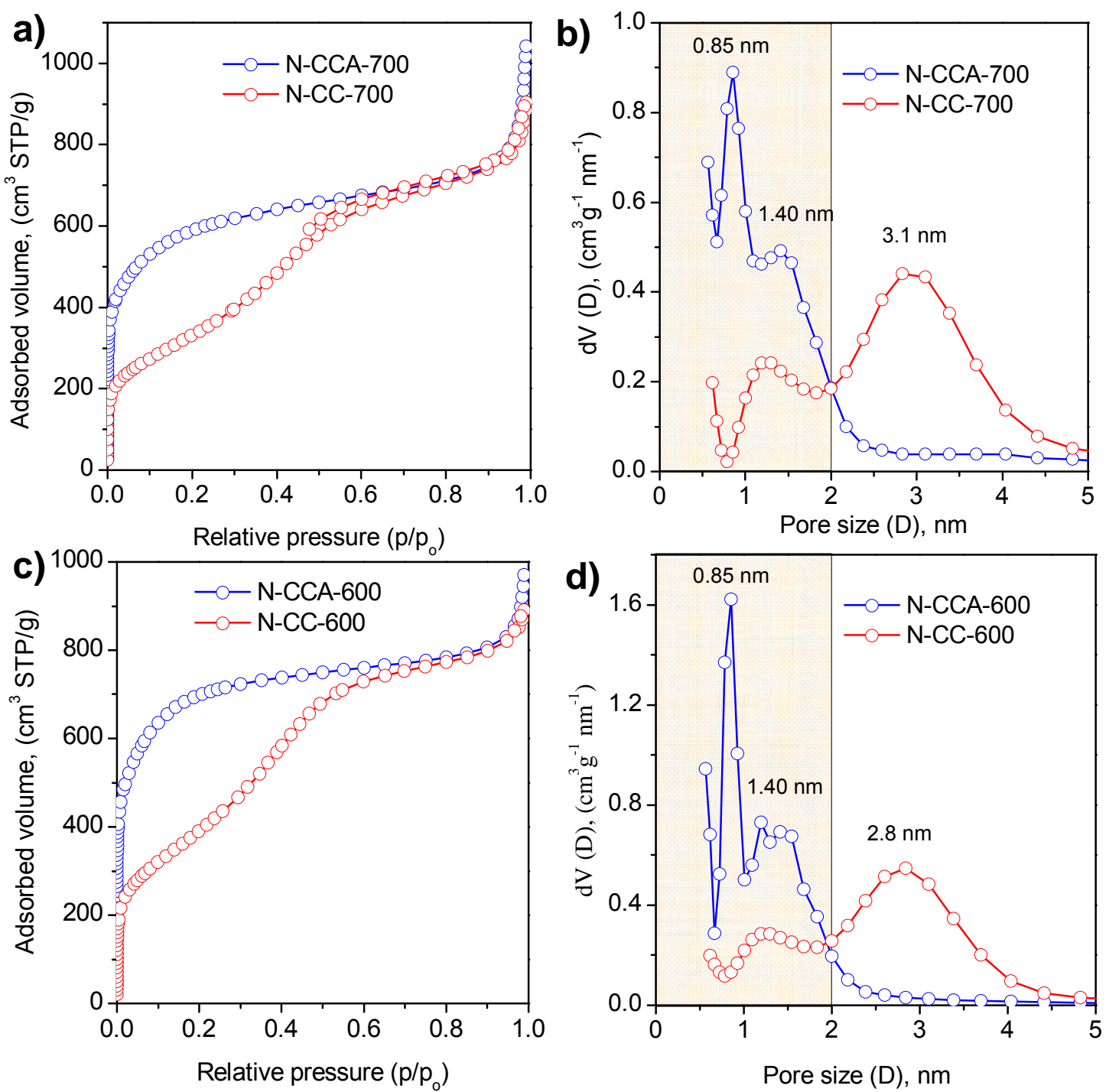

Figure 4. $(a, c)$ Nitrogen sorption isotherms and $(b, d)$ pore size distributions of the template and post-activated carbon capsules. The grey region in (b) and (d) corresponds to the micropore size range. 


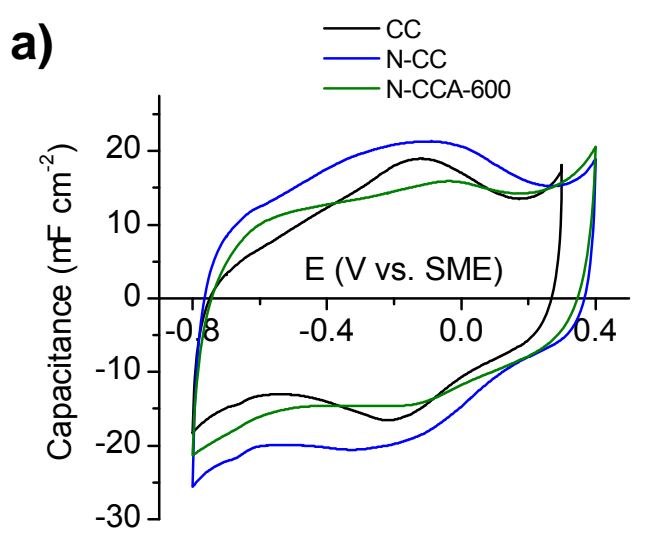

b)

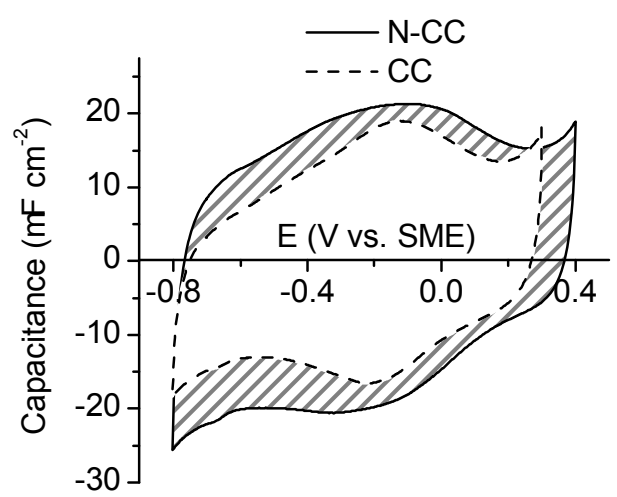

Figure 5. (a) Three-electrode cyclic voltammograms $\left(2 \mathrm{mV} \mathrm{s}^{-1}\right)$ for the CC, N-CC and $\mathrm{N}-\mathrm{CCA}-600$ samples in $1 \mathrm{M} \mathrm{H}_{2} \mathrm{SO}_{4}$ and (b) Illustration of the pseudocapacitance contribution (shaded region) of the $\mathrm{N}$-groups in $\mathrm{N}$-CC sample. 


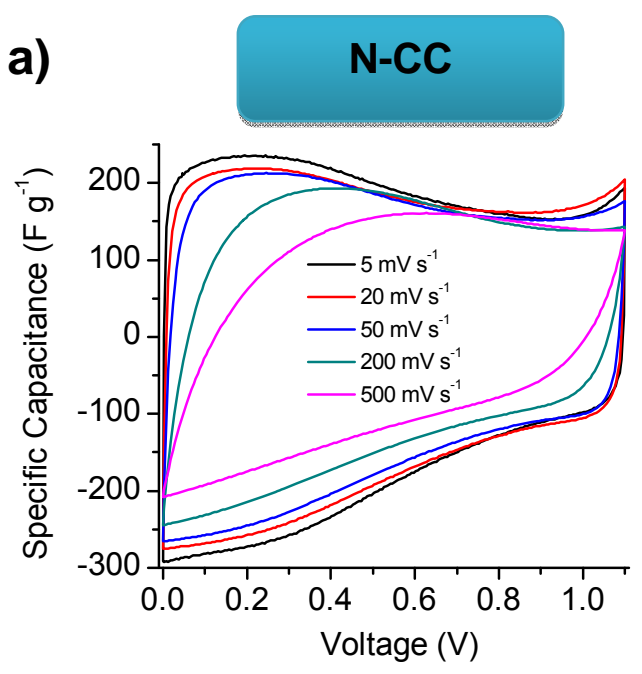

c)

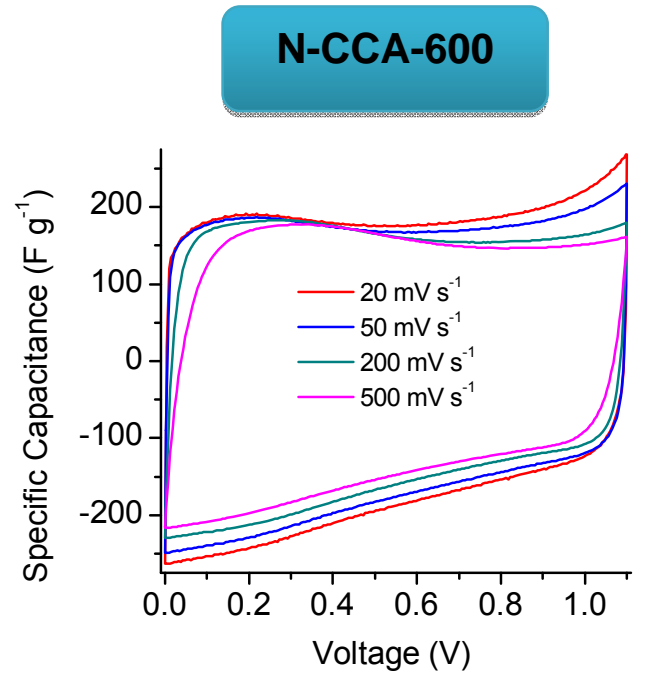

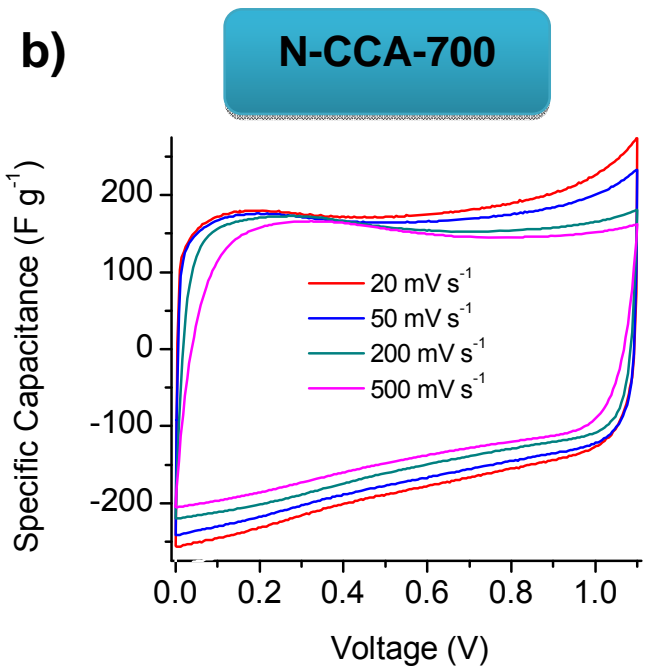

d)

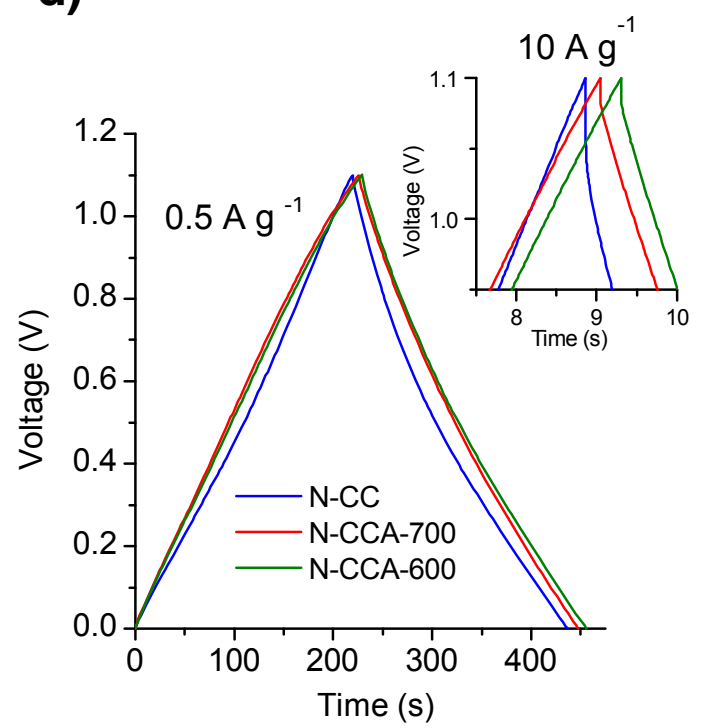

Figure 6. Cyclic voltammograms at different scan rates for (a) N-CC, (b) NCCA-700 and (c) N-CCA-600, and (d) charge-discharge voltage profiles at $0.5 \mathrm{~A}$ $\mathrm{g}^{-1}$ and $10 \mathrm{~A} \mathrm{~g}^{-1}$ (inset). Electrolyte: $1 \mathrm{M} \mathrm{H}_{2} \mathrm{SO}_{4}$. 


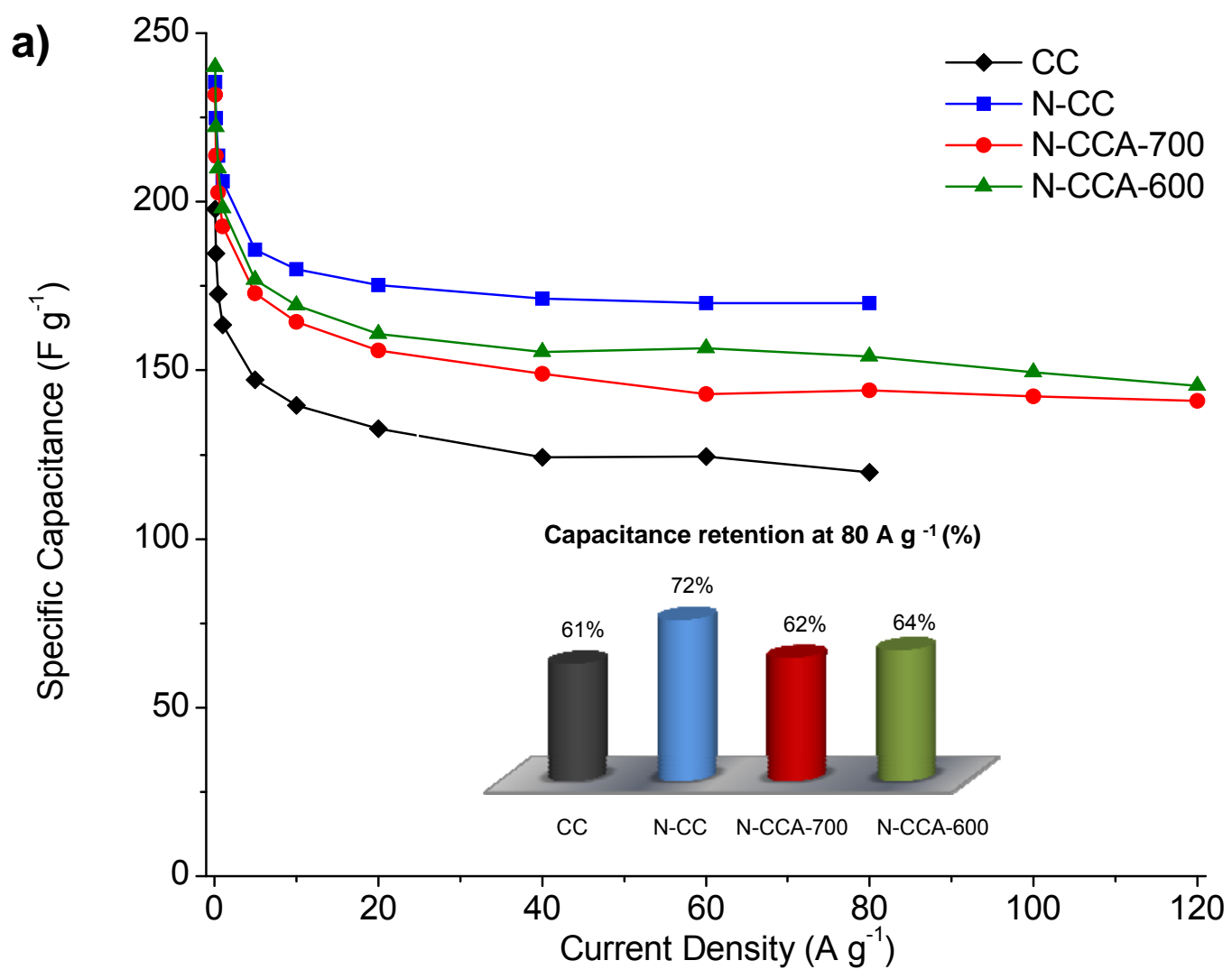

Figure 7. (a) Variation of specific capacitance with increasing discharge current density for the N-doped carbon capsules N-CC, N-CCA-700, N-CCA-600 and the undoped carbon capsules (CC) at $1.1 \mathrm{~V}$ in $1 \mathrm{M} \mathrm{H}_{2} \mathrm{SO}_{4}$. Inset: percentage of capacitance retention at $80 \mathrm{~A} \mathrm{~g}^{-1}$. 


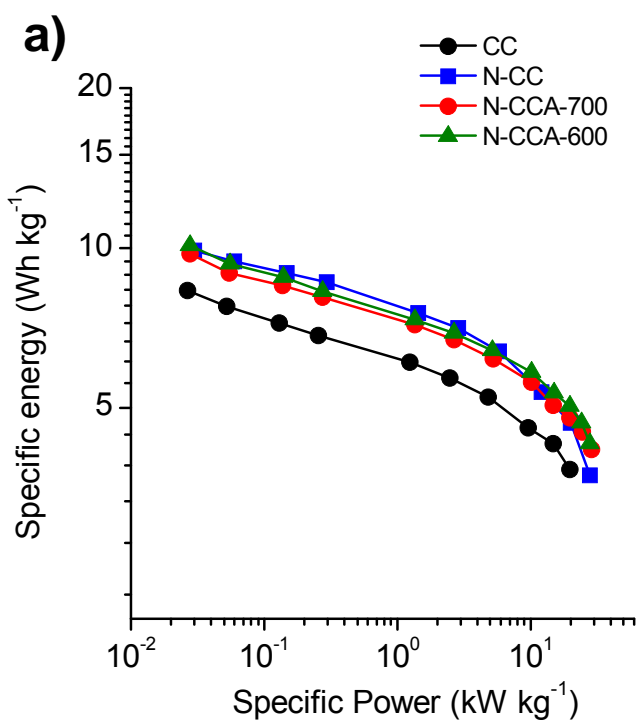

b)

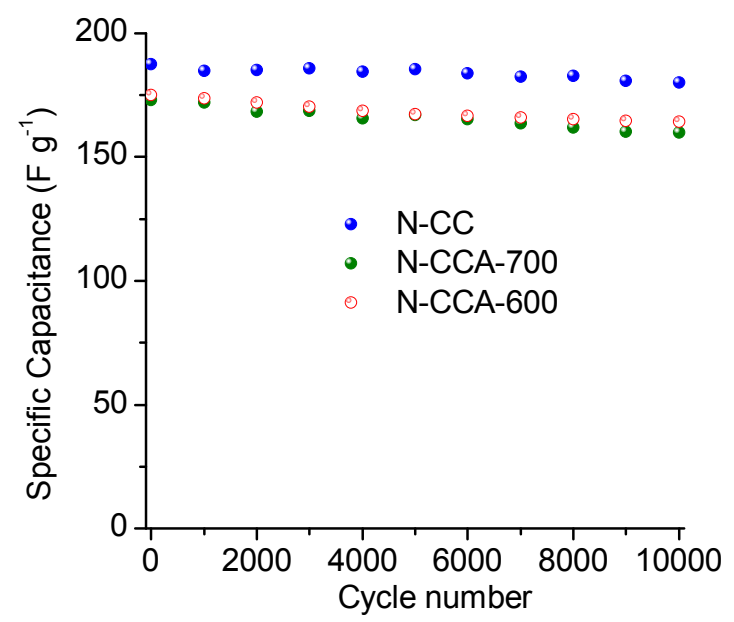

Figure 8. (a) Ragone plot and (b) long-term stability under cycling at $5 \mathrm{~A} \mathrm{~g}^{-1}$ of the $\mathrm{N}$-doped carbon capsules at $1.1 \mathrm{~V}$ in $1 \mathrm{M} \mathrm{H}_{2} \mathrm{SO}_{4}$. 

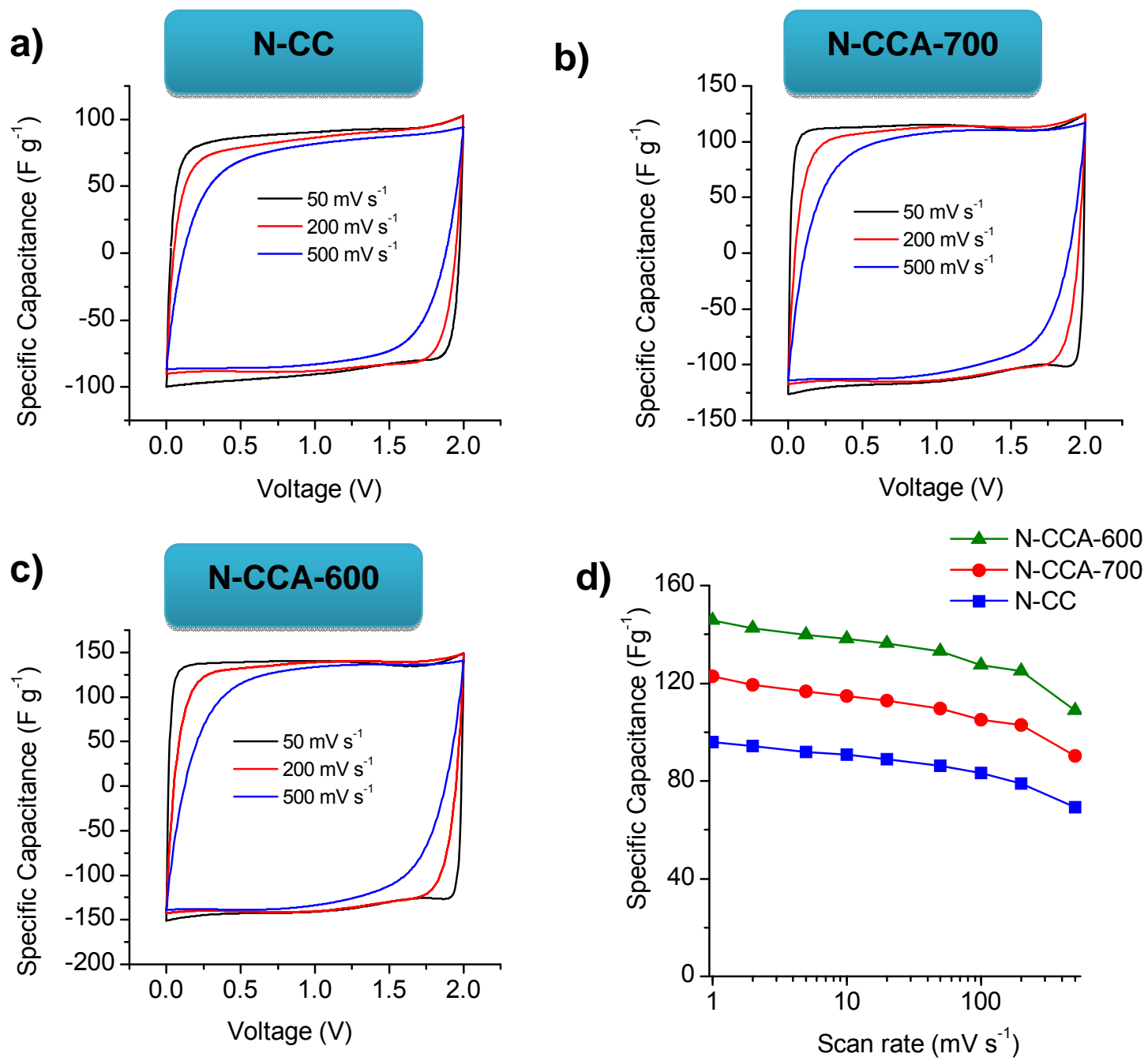

Figure 9. (a, b, c) Cyclic voltammograms at different scan rates and (d) variation of the specific capacitance with the increase in the scan rate for the $\mathrm{N}$ doped carbon capsules in $1 \mathrm{M} \mathrm{TEABF}_{4}$. 

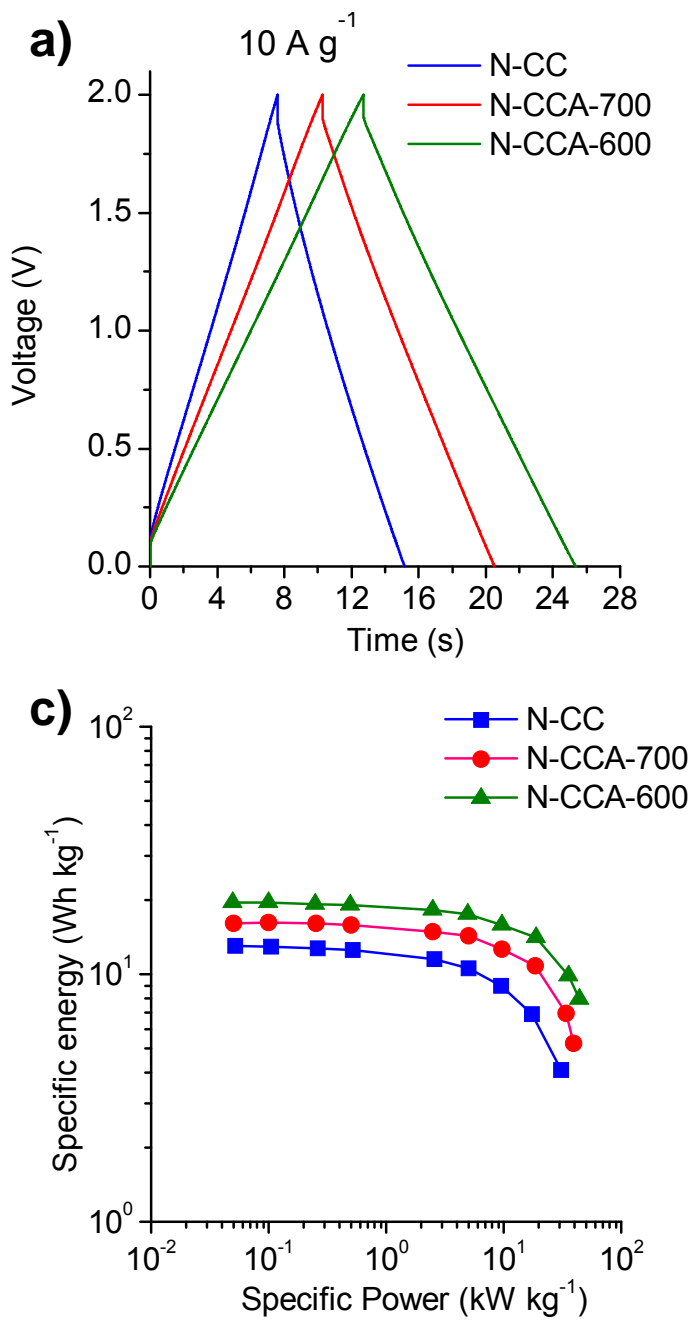

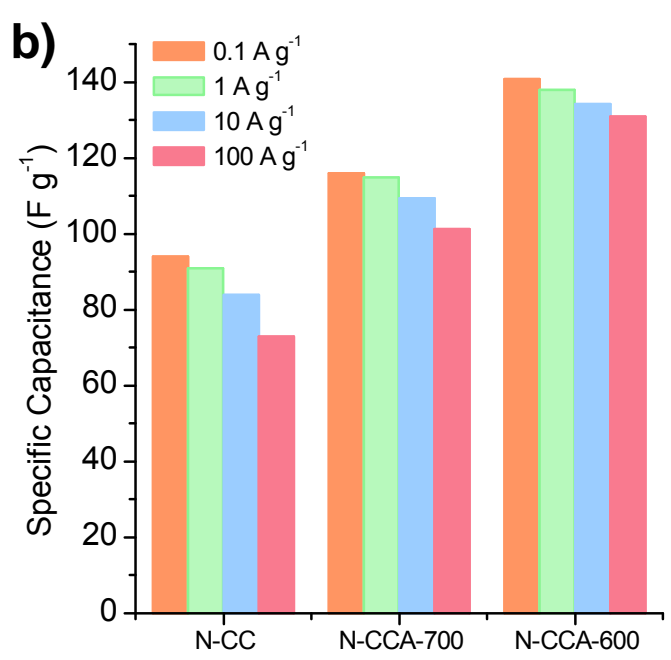

d)

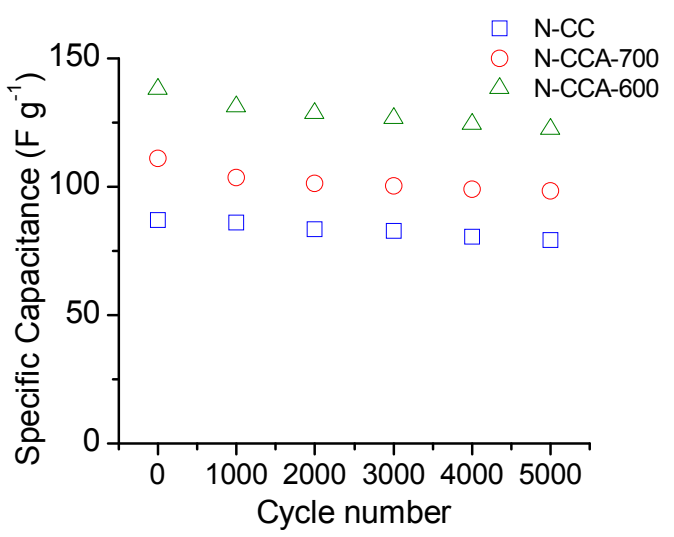

Figure 10. (a) Charge discharge voltage profile at $10 \mathrm{~A} \mathrm{~g}^{-1}$, (b) variation in specific capacitance with increasing discharge current density, (c) Ragone plot and (d) long-term stability under cycling at $5 \mathrm{~A} \mathrm{~g}^{-1}$ for the $\mathrm{N}$-doped carbon capsules in $1 \mathrm{M} \mathrm{TEABF}_{4}$. 


\section{References}

1 E. Frackowiak, Phys. Chem. Chem. Phys., 2007, 9, 1774-1785.

2 A. G. Pandolfo and A. F. Hollenkamp, J. Power Sources, 2006, 157, 1127.

3 F. Beguin, V. Presser, A. Balducci and E. Frackowiak, Adv Mater, 2014, 26, 2283.

4 J. Chmiola, G. Yushin, Y. Gogotsi, C. Portet, P. Simon and P. L. Taberna, Science, 2006, 313, 1760-1763.

5 J. Wang and S. Kaskel, J. Mater. Chem., 2012, 22, 23710-23725.

6 C. O. Ania, V. Khomenko, E. Raymundo-Piñero, J. B. Parra and F. Béguin, Adv. Funct. Mater., 2007, 17, 1828-1836.

7 F. Ma, H. Zhao, L. Sun, Q. Li, L. Huo, T. Xia, S. Gao, G. Pang, Z. Shi and S. Feng, J. Mater. Chem., 2012, 22, 13464-13468.

8 A. Ghosh and Y. H. Lee, ChemSusChem, 2012, 5, 480-499.

9 Z. Wang, F. Li and A. Stein, Nano Letters, 2007, 7, 3223-3226.

10 Y. Fang, D. Gu, Y. Zou, Z. Wu, F. Li, R. Che, Y. Deng, B. Tu and D. Zhao, Angew. Chem. Int. Ed., 2010, 49, 7987-7991.

11 X.-Q. Zhang, Q. Sun, W. Dong, D. Li, A.-H. Lu, J.-Q. Mu and W.-C. Li, J. Mater. Chem. A, 2013, 1, 9449-9455.

12 L.-F. Chen, X.-D. Zhang, H.-W. Liang, M. Kong, Q.-F. Guan, P. Chen, Z.Y. Wu and S.-H. Yu, ACS Nano, 2012, 6, 7092-7102.

13 M. D. Stoller, S. Park, Y. Zhu, J. An and R. S. Ruoff, Nano Letters, 2008, 8, 3498-3502.

14 M. Sevilla and A. B. Fuertes, ACS Nano, 2014, 8, 5069-5078. 
15 G. Büchel, K. K. Unger, A. Matsumoto and K. Tsutsumi, Adv. Mater., 1998, 10, 1036-1038.

16 S. B. Yoon, K. Sohn, J. Y. Kim, C. H. Shin, J. S. Yu and T. Hyeon, Adv. Mater., 2002, 14, 19-21.

17 P. Valle-Vigon, M. Sevilla and A. B. Fuertes, Chem. Mater., 2010, 22, 2526-2533.

18 M. Kruk, M. Jaroniec and A. Sayari, Langmuir, 1997, 13, 6267-6273.

19 M. Jaroniec, M. Kruk and J. P. Olivier, Langmuir, 1999, 15, 5410-5413.

20 M. Kruk, M. Jaroniec and K. P. Gadkaree, J. Colloid Interface Sci., 1997, $192,250-256$.

21 M. Sevilla and A. B. Fuertes, Carbon, 2006, 44, 468-474.

22 M. Sevilla, C. Sanchis, T. Valdes-Solis, E. Morallon and A. B. Fuertes, J. Phys. Chem. C, 2007, 111, 9749-9756.

23 A. Ōya and H. Marsh, J. Mater. Sci, 1982, 17, 309-322.

24 H. Marsh, D. Crawford and D. W. Taylor, Carbon, 1983, 21, 81-87.

25 J. Ozaki, M. Mitsui and Y. Nishiyama, Carbon, 1998, 36, 131-135.

26 J. R. Pels, F. Kapteijn, J. A. Moulijn, Q. Zhu and K. M. Thomas, Carbon, 1995, 33, 1641-1653.

27 H. Schmiers, J. Friebel, P. Streubel, R. Hesse and R. Köpsel, Carbon, 1999, 37, 1965-1978.

28 V. Ruiz, C. Blanco, E. Raymundo-Piñero, V. Khomenko, F. Béguin and R. Santamaría, Electrochim. Acta, 2007, 52, 4969-4973.

29 E. Raymundo-Piñero, M. Cadek and F. Béguin, Adv. Funct. Mater., 2009, 19, 1032-1039.

30 C. T. Hsieh and H. Teng, Carbon, 2002, 40, 667-674. 
31 Y.-H. Lee, K.-H. Chang and C.-C. Hu, J. Power Sources, 2013, 227, 300308.

32 D.-W. Wang, F. Li, L.-C. Yin, X. Lu, Z.-G. Chen, I. R. Gentle, G. Q. Lu and H.-M. Cheng, Chem. Eur. J., 2012, 18, 5345-5351.

33 A. B. Fuertes, G. A. Ferrero and M. Sevilla, J. Mater. Chem. A, 2014, 2, 14439-14448.

34 J. W. Lee, J. M. Ko and J.-D. Kim, Electrochim. Acta, 2012, 85, 459-466.

35 W. Kim, J. B. Joo, N. Kim, S. Oh, P. Kim and J. Yi, Carbon, 2009, 47, $1407-1411$.

36 W. Kim, M. Y. Kang, J. B. Joo, N. D. Kim, I. K. Song, P. Kim, J. R. Yoon and J. Yi, J. Power Sources, 2010, 195, 2125-2129.

37 G. Lota, K. Lota and E. Frackowiak, Electrochem. Commun., 2007, 9, 1828-1832.

38 E. Frackowiak, G. Lota, J. Machnikowski, C. Vix-Guterl and F. Béguin, Electrochim. Acta, 2006, 51, 2209-2214.

39 F. Béguin, K. Szostak, G. Lota and E. Frackowiak, Adv. Mater., 2005, 17, 2380-2384.

40 P. Simon, Y. Gogotsi, Acc. Chem. Res., 2013, 46, 1094-1103.

41 Y. S. Yun, S. Y. Cho, J. Shim, B. H. Kim, S.-J. Chang, S. J. Baek, Y. S. Huh, Y. Tak, Y. W. Park, S. Park and H.-J. Jin, Adv. Mater., 2013, 25, 1993-1998.

42 D. Puthusseri, V. Aravindan, S. Madhavi and S. Ogale, Energy Environ. Sci., 2014, 7, 728-735.

43 Y. Li, Z. Li and P. K. Shen, Adv. Mater., 2013, 25, 2474-2480. 
44 M. D. Stoller, S. Park, Z. Yanwu, J. An and R. S. Ruoff, Nano Letters, 2008, 8, 3498-3502.

45 Q. Li, R. Jiang, Y. Dou, Z. Wu, T. Huang, D. Feng, J. Yang, A. Yu and D. Zhao, Carbon, 2011, 49, 1248-1257.

46 D. Bhattacharjya, M.-S. Kim, T.-S. Bae and J.-S. Yu, J. Power Sources, 2013, 244, 799-805. 